Original article

\title{
PREGNANCY RATE IN DRY AND LACTATING GOATS AFTER ESTRUS SYNCHRONISATION WITH ARTIFICIAL INSEMINATION AND NATURAL BREEDING (A FIELD STUDY)
}

\author{
S. YOTOV ${ }^{1}$, A. ATANASOV ${ }^{1}$, M. KARADAEV ${ }^{1}$, L. DIMOVA $^{2}$ \\ \& D. VELISLAVOVA ${ }^{2}$
}

${ }^{1}$ Department of Obstetrics, Reproduction and Reproductive Disorders; ${ }^{2}$ Fourth year student; Faculty of Veterinary Medicine, Trakia University, 6000 Stara Zagora, Bulgaria

\section{Summary}

Yotov, S., A. Atanasov, M. Karadaev, L. Dimova \& D. Velislavova, 2016. Pregnancy rate in dry and lactating goats after estrus synchronisation with artificial insemination and natural breeding (a field study). Bulg. J. Vet. Med., 19, No 3, 218-223.

The objective of this study was to determine the pregnancy rate in dry and lactating goats after estrus synchronisation with artificial insemination and natural breeding of unconceived animals. The investigation was conducted with 75 dry (group I) and 32 lactating (group II) local goats in breeding season. All animals were submitted to estrus synchronisation by intravaginal sponges for 12 days, PMSG injection on day of sponge removal and two artificial inseminations (AI) with fresh semen -48 and 56 hours after sponge withdrawal. Two weeks after the AI, daily test for goats which had not conceived after the AI was performed by teaser and the detected animals in estrus were naturally mated with a fertile buck. Ultrasonographic pregnancy examination was carried out at 20-day intervals until day 100 after the AI. The pregnancy rate in artificially inseminated and naturally bred animals and the interestrus intervals were calculated. The pregnancy rate between both synchronised groups differed significantly $(\mathrm{P}<0.05)$, while the values in the groups with natural breeding were comparable. Different pregnancy rates between artificially inseminated and naturally bred goats in group I $(72 \% \mathrm{vs}$. $42.9 \%)$ and group II $(19 \%$ vs. $73 \%)$ were registered $(\mathrm{P}<0.05)$. Additionally, considerable differences $(\mathrm{P}<0.05)$ between the values after first natural breeding $(9.6 \%$ and $46.6 \%)$ were detected. The total pregnancy rate $(84 \%)$ in dry goats was higher $(\mathrm{P}<0.05)$ than that $(54 \%)$ in lactating animals. The interestrus intervals were similar $(\mathrm{P}=0.2)$. In conclusion, the current data could be used for optimisation of the pregnancy rate and the reproductive efficiency in local goat breeds.

Key words: estrus synchronisation, goats, pregnancy rate

\section{INTRODUCTION}

Accelerated introduction of new reproduction biotechnologies has been accepted as a prerequisite for high economical effi- ciency in intensive goat breeding (Leboeuf et al., 1998; Holtz, 2005; Mellado et al., 2006; Paramio \& Izquierdo, 2014). 
Estrus synchronisation (ES), artificial insemination (AI) and ultrasound check of reproductive system are important management tools that have been used to improve reproductive performance in goats (Riaz et al., 2012; Pietroski et al., 2013; Fasulkov, 2014; Arredondo et al., 2015). One of the most important indicators for success after introduction of the aforementioned biotechnological methods is the increase in pregnancy and kidding rates (Leboeuf et al., 2008; Arrebola et al., 2012; Uzabaci et al., 2014). Various factors affecting pregnancy have been reported but the genetic and environmental factors (animal breed, photoperiod, temperature, etc.) were shown to be of primary importance in most of the studies (Mellado et al., 2004, 2006; Salvador et al., 2005). Controversial pregnancy results (from 40 to $72.2 \%$ ) have been determined in dairy goats with synchronised oestrus and artificial insemination by several authors (Dogan et al., 2005; Saribay et al., 2011, Tasdemir et al., 2011; Ciptadi et al., 2014). In most of the experiments different factors (season, breed, age and body condition score of the animals, estrus synchronisation protocol, time and number of AI and the breeding technology) have been shown as a cause for varying results (Dogan et al., 2005; Mellado et al., 2006; Martemucci \& D'Alessandro, 2011; Nunes \& Salgueiro, 2011; Ciptadi et al., 2014).

The information about pregnancy rates in dry and lactating goats from local breeds is insufficient. The objective of this study was therefore to determine the pregnancy rate in dry and lactating goats after estrus synchronisation with artificial insemination and natural breeding of unconceived animals.

\section{MATERIALS AND METHODS}

The study was conducted with 107 clinically healthy Bulgarian White dairy goats and local crosses, aged 2-4 years, weighing $45-50 \mathrm{~kg}$ and housed in the same place (closed barn, separated in sections with access to farmyard for walk). The dry (group I; $\mathrm{n}=75$ ) and lactating (group II; $\mathrm{n}=32$ ) goats received a ration for dry and lactating goats, respectively, and water $a d$ libitum. The milking process was done twice - morning and evening in a milking parlour. The farm was located at a latitude $\mathrm{N} 42^{\circ} 25^{\prime}$ and a longitude E $25^{\circ} 37^{\prime}$. The experiment was done during the breeding season (September-December).

All animals were submitted to estrus synchronisation by intravaginal sponges, containing $30 \mathrm{mg}$ fluorogestone acetate (Syncro-part, Ceva Animal Health, France) for 12 days and injection of 500 IU (Syncro-part PMSG, Ceva Animal Health, France) on day of sponge removal. Semen was collected using an artificial vagina immediately before insemination from two bucks proved to be fertile. Fresh semen with no deviations in macroscopic parameters was used: $>1.6 \times 10^{9}$ spermatozoa $/ \mathrm{mL},>80 \%$ motile spermatozoa, $<20 \%$ abnormal spermatozoa in the ejaculate and no agglutination. Fresh semen was diluted with TFC-based extender with soybean lecithin (Yotov, 2015), and after the final dilution, a single AI dose of $0.4 \mathrm{~mL}$ contained $160 \times 10^{6}$ motile spermatozoa. During AI, semen was stored at a water bath at $37{ }^{\circ} \mathrm{C}$. Artificial insemination was made twice, 48 and $56 \mathrm{~h}$ after sponge withdrawal. Two weeks after the AI, goats that have not conceived were submitted to a daily test by a teaser and the detected animals in estrus were naturally mated by fertile bucks. 
Pregnancy rate in dry and lactating goats after estrus synchronisation with artificial insemination....

Ultrasonographic pregnancy examinations were carried out at a 20-day interval until day 100 after the AI by scanner A5 Vet SonoScape (SonoScape, Co. LTD, Shenzhen, China) with a linear probe 5-12 $\mathrm{MHz}$ frequency. The positive pregnancy diagnosis was based on visualisation of embryo/foetus and placentomas in the fluid-filled uterine lumen. The pregnancy rate in artificially inseminated and naturally bred animals and interestrus intervals were calculated.

Statistical processing was performed by means of non-parametric analysis for comparison of two means and proportions, using Student's $t$-criterion (Stat-Soft 1984-2000 Inc. statistical software). Differences were considered significant when $\mathrm{P}$ values were $<0.05$.

\section{RESULTS}

The pregnancy rate between both synchronised groups $(72 \%$ vs. $19 \%)$ differed significantly $(\mathrm{P}<0.05)$, while the values in the naturally bred groups $(42.9 \%$ and $73.3 \%)$ did not $(\mathrm{P}=0.08)$ (Table 1). Significant differences $(\mathrm{P}<0.05)$ in the pregnancy rates between artificially insemi- nated and naturally bred goats within each of the groups were also registered. The pregnancy results after the first and the second natural breeding in dry goats $(9.6 \%$ and $33.3 \%)$ and in lactating animals (46.6\% and $26.7 \%$ ) did not differ considerably $(\mathrm{P}=0.1 ; \mathrm{P}=0.2)$. However, the values after the first natural breeding differed significantly between the dry and lactating groups $(\mathrm{P}<0.05)$. The total pregnancy rate $(84 \%)$ in dry goats was higher $(\mathrm{P}<0.05)$ than that $(53 \%)$ in lactating animals. Until day 100 after artificial insemination, $16 \%$ and $47 \%$ of the animals from the first and second group, respectively, were recorded as non-pregnant. The average interestrus intervals in the dry group (18.9 \pm 1.4 days) tended to be shorter, compared to that (20.7 \pm 2.5 days) in the lactating group, but a statistically significant difference was not determined $(\mathrm{P}=0.2)$.

\section{DISCUSSION}

The current study was designed to determine the pregnancy rate in dry and lactating goats after estrus synchronisation with artificial insemination and after natural breeding of the unconceived animals. The

Table 1. Pregnancy rate, non-pregnant animals and interestrus interval in dry and lactating goats

\begin{tabular}{lcc}
\hline Reproductive parameters & $\begin{array}{c}\text { Group I } \\
\text { dry goats) }\end{array}$ & $\begin{array}{c}\text { Group II } \\
\text { (lactating goats) }\end{array}$ \\
\hline $\begin{array}{l}\text { Pregnancy rate after estrus synchronisation and } \\
\text { artificial insemination, \% (n) }\end{array}$ & $72(54 / 75)^{1 \mathrm{~A}}$ & $19(6 / 32)^{2 \mathrm{~A}}$ \\
Pregnancy rate after natural breeding - \% (n) & $42.9(9 / 21)^{1 \mathrm{~B}}$ & $73.3(11 / 15)^{1 \mathrm{~B}}$ \\
First natural breeding & $9.6(2 / 21)^{1 \mathrm{~A}}$ & $46.6(7 / 15)^{2 \mathrm{~A}}$ \\
Second natural breeding & $33.3(7 / 21)^{1 \mathrm{~A}}$ & $26.7(4 / 15)^{1 \mathrm{~A}}$ \\
Total pregnancy rate, \% (n) & $84(63 / 75)^{1}$ & $53(17 / 32)^{2}$ \\
Non-pregnant goats, \% (n) & $16(12 / 75)^{1}$ & $47(15 / 32)^{2}$ \\
Interestrus interval (mean \pm SD), days & $18.9 \pm 1.4^{1}$ & $20.7 \pm 2.5^{1}$ \\
\hline
\end{tabular}

Different numbers within the same row and different letters within the same column indicate significant differences $(\mathrm{P}<0.05)$. 
significantly higher pregnancy rate in group I than in group II indicated better response of the dry goats after the applied synchronisation treatment. Probably, the lactation was a main factor for unsatisfactory pregnancy rate in lactating goats.

Increased milk yield could be a reason for accelerated metabolism of progesterone resulting in failed ovulation or early embryo loss. The lactation influences the fertility through functional pathways related to energy intake or linkage of genes and may conduct to different hormonal and metabolic changes (Veerkamp et al., 2003; Serin et al., 2010). Mellado et al. (2005) reported that the prolonged milk synthesis during the dry season caused a significant reduction in pregnancy rate in lactating does with high prenatal wastage and lower foetal survival.

The greater pregnancy rate in the lactating group after natural estrus and breeding, compared to that obtained after estrus synchronisation and the insignificant difference in pregnancy rates between the groups supported the aforementioned hypothesis. It could be explained with higher percentage of successful ovulations in natural estrus, better synchronisation between time of ovulation and semen application or higher number of fertile spermatozoa per insemination. Advantage of natural breeding in comparison with $\mathrm{AI}$ in lactating goats has also been shown by Uzabaci et al. (2014). Significantly higher pregnancy rate $(46.6 \%)$ in group II after the first natural breeding, compared to the value $(9.6 \%)$ in group I could be attributed to increased pregnancy failure in group I. Chao et al. (2008) determined a high incidence of short luteal lifespan of the first estrous cycle after estrus synchronisation in goats and explained embryonic loss with the instability of the luteal lifespan. This could be an explanation for the unsatisfactory number of pregnant goats after mating in group I. The present findings did not determine significant difference between the interestrus intervals (18.9 \pm 1.4 and $20.7 \pm 2.5$ days) in unconceived goats, but there was a tendency towards shorter first estrous cycle after estrus synchronisation in dry goats. The similar pregnancy results after the second natural breeding could be accepted as indicator for normal duration of the second estrous cycle with adequate ovulation and corpus luteum lifespan. The considerably higher total pregnancy rate (84\%) in group I was in agreement with another study reporting better pregnancy rate in dry than in lactating goats (Mellado et al., 2005). The analysis shows that the achievement of good reproductive efficiency requires a different approach in the insemination schedule of dry and lactating goats under field conditions.

In conclusion, the current data could be used for optimisation of the pregnancy rate and the reproductive efficiency in local goat breeds.

\section{REFERENCES}

Arrebola, F. A., B. Pardo, M. Sanches, M. D. Lopez \& C. C. Perez-Marin, 2012. Factor influencing the success of an artificial insemination programme in Florida goats. Spanish Journal of Agricultural Research, 10, 338-344.

Arredondo, A. J. G., A. G. Gomez, J. F. Vazcuez-Armijo, R. A. Ledezma-Torres, H. Bernal-Barragan \& F. Sanchez-Davila, 2015. Status and implementation of reproductive technologies in goats in emerging countries. African Journal of Biotechnology, 14, 719-727.

Chao, L. M., K. Takayama, Y. Nakanishi, K. Hamana, M. Takagi, C. Kubota \& T. Kojima, 2008. Luteal lifespan and fertility 
Pregnancy rate in dry and lactating goats after estrus synchronisation with artificial insemination....

after estrus synchronization in goats. Journal of Veterinary Science, 9, 95-101.

Ciptadi, G., A. Budiarto, M. N. Ihsan, U. Wisaptiningsih \& S. Wahyuningsih, 2014. Reproductive performance and success of artificial insemination in Indonesian crossbreed goats in research versus small holder farm. American-Eurasian Journal of Sustainable Agriculture, 8, 35-38.

Dogan, I., Z. Nur, U. Gunay, H. Sagirkaya, M. K. Soylu \& C. Sonmez, 2005. Estrus synchronization during the natural breeding season in Anatolian black does. Veterinary Medicine (Prague), 50, 33-38.

Fasulkov, I., 2014. Ultrasonography of uterine involution in goats. Journal of the Faculty of Veterinary Medicine, Istanbul University, 40, 63-69.

Holtz, W., 2005. Recent developments in assisted reproduction in goats. Small Ruminant Research, 60, 95-110.

Leboeuf, B., E. Manfredi, P. Boue, A. Piac'ere, G. Brice, G. Baril, C. Broqua, P. Humblot \& M. Terqui, 1998. Artificial insemination of dairy goats in France. Livestock Production Science, 55, 193-203.

Leboeuf, B., J. A. Delgadillo, E. Manfredi, A. Piacère, V. Clément, P. Martin, M. Pellicer, P. Boué \& R. de Cremoux, 2008. Management of goat reproduction and insemination for genetic improvement in France. Reproduction in Domestic Animals, 43 (Suppl. 2), 379-385.

Martemucci, G., \& A. G. D'Alessandro, 2011. Induction/synchronization of oestrus and ovulation in dairy goats with different short term treatments and fixed time intrauterine or exocervical insemination system. Animal Reproduction Science, 126, 187-194.

Mellado, M., R. Valdez, L. M. Lara \& J. E. Garcia, 2004. Risk factors involved in conception, abortion, and kidding rates of goats under extensive conditions. Small Ruminant Research, 55, 191-198.

Mellado, M., L. Olivares, R. Lopez \& J. Mellado, 2005. Influence of lactation, liveweight and lipid reserves at mating on re- productive performance of grazing goats. Journal of Animal and Veterinary Advances, 4, 420-423.

Mellado, M., J. E. Valdez, J. E. Garcia, R. Lopez \& A. Rodriguez, 2006. Factors affecting the reproductive performance of goats under intensive conditions in a hot arid environment. Small Ruminant Research, 6, 110-118.

Nunes, J. F. \& C. C. M. Salgueiro, 2011. Strategies to improve the reproductive efficiency of goats in Brazil. Small Ruminant Research, 98, 176-184.

Paramio, M.-T. \& D. Izquierdo, 2014. Assisted reproduction technologies in goats. Small Ruminant Research, 121, 21-26.

Pietroski, A. C. C. A., F. Z. Brandão, J. M. G. de Souza \& J. F. da Fonseca, 2013. Short, medium or long-term hormonal treatments for induction of synchronized estrus and ovulation in Saanen goats during the nonbreeding season. Revista Brasiliera Zootecnica, 42, 168-173.

Riaz, H., A. Sattar, M. A. Arshad \& N. Ahmad, 2012. Effect of synchronization protocols and GnRH treatment on the reproductive performance in goats. Small Ruminant Research, 104, 151-155.

Saribay, M. K., F. Karaca, G. Dogruer, Y. Ergun, Y., I. Yavas \& S. T. Ates, 2011. Oestrus synchronization by short and longterm intravaginal sponge treatment in lactating goats during the breeding season: The effects of GnRH administrations immediately after matings on fertility. Journal of Animal and Veterinary Advances, 10, 3134-3139.

Salvador, I., M. P. Viudes-de-Castro, J. Bernacer, E. A. Gomez \& M. A. Silvestre, 2005. Factors affecting pregnancy rate in artificial insemination with frozen semen during non-breeding season in MurcianoGranadina goats: A field assay. Reproduction in Domestic Animals, 40, 526-529.

Serin, I., G. Serin, M. Yilmaz, F. Kiral \& A. Ceylan, 2010. The effects of body weight, body condition score, age, lactation, serum trygliceride, cholesterol and paraoxonase 
levels on pregnancy rate of Saanen goats in breeding season. Journal of Animal and Veterinary Advances, 9, 1848-1851.

Tasdemir, U., A. A. Reha, M. Kaymaz \& K. Karakas, 2011. Ovarian response and embryo yield of Angora and Lilis goats given the day 0 protocol or superovulation in the non-breeding season. Tropical Animal Health and Production, 43, 1035-1038.

Uzabaci, E., K. Çubukçu \& S. Dikmen, 2014. Determination of factors affecting pregnancy rate in Turkish Saanen goats. Veterinary Journal of Ankara University, 61, 303-307.

Veerkamp, R. F., B. Beerda, \& T. van der Lende, 2003. Effects of genetic selection for milk yield on energy balance, levels of hormones, and metabolites in lactating cattle, and possible links to reduced fertility. Livestock Production Science, 83, 257275.
Yotov, S., 2015. Effect of TFC-based extenders with soybean lecithin and/or low concentration of glycerol on the quality of goat chilled-stored semen. International Journal of Current Microbiology and Applied Science, 4, 752-761.

Paper received 01.06.2015; accepted for publication 25.09.2015

\section{Correspondence:}

Assoc. Prof. Stanimir Yotov PhD Department of Obstetrics, Reproduction and Reproductive Disorders,

Faculty of Veterinary Medicine, Student's Campus, Trakia University 6000 Stara Zagora, Bulgaria e-mail: stanrad@abv.bg 